\title{
Journal of Experimental \& Clinical

\section{Correction: Dark Aberrant Crypt Foci with activated Wnt pathway are related to tumorigenesis in the colon of AOM-treated rat Qing Lu ${ }^{1,2}$, Bo Jiang*1, Chen $\operatorname{Lin}^{1}$ and Tao Shan ${ }^{1}$}

Address: ${ }^{1}$ The Institute for Digestive Medicine, Nanfang Hospital, Southern Medical University, Guangzhou 510515, PR China and ${ }^{2}$ Department of Gastroenterology, Guilin Medical College affiliated hospital, Guilin 541001, PR China

Email: Qing Lu - qinglu76@163.com; Bo Jiang* - drjiang@163.com; Chen Lin - jocky0606@163.com; Tao Shan - hezhuokai@163.com

* Corresponding author

Published: 25 September 2008

Journal of Experimental \& Clinical Cancer Research 2008, 27:47 doi:10.1 I86/I756-9966-27-47

This article is available from: http://www.jeccr.com/content/27///47

(c) 2008 Lu et al; licensee BioMed Central Ltd.

This is an Open Access article distributed under the terms of the Creative Commons Attribution License (http://creativecommons.org/licenses/by/2.0), which permits unrestricted use, distribution, and reproduction in any medium, provided the original work is properly cited.

In our recent article [1], we did not identify several paragraphs in the background and methods that were reproduced from an article by Paulsen et al. [2]. Specifically sections of paragraphs 1 and 2 of the Background were reproduced, as well parts of the sections in the Methods, which describe scoring of classic ACF, dark ACF and tumors, histopathological analysis, and immunohistochemical analysis.

We would also like to acknowledge that what we refer to as Dark ACF in our article is the same as that which Paulsen et al. identified as Flat ACF in their article [2].

We apologise to Paulsen et al. and regret any inconvenience caused by our failure to acknowledge their work.

\section{References}

I. Lu Q, Jiang Bo, Lin C, Shan T: Dark Aberrant Crypt Foci with activated Wnt pathway are related to tumorigenesis in the colon of AOM-treated rat. J Exp Clin Cancer Res 2008, 27:26.

2. Paulsen JE, Loberg EM, Olstern HB, Knutsen H, Steffensen IL, Alexander J: Flat Dysplastic Aberrant Crypt Foci Are Related to Tumorigenesis in the Colon of Azoxymethane-Treated Rat. Cancer Res 2005, 65(I): 121-129.
Received: 25 September 2008

Accepted: 25 September 2008 